\title{
ATIVISMO POLÍTICO E JUVENTUDE: CATRACAS NA ESCOLA E NA CIDADE PARA OS JOVENS MAIS JOVENS
}

Miriam Leite (UERJ)*

\begin{abstract}
RESUMO
Os movimentos de ocupação urbana ocorridos em diversas partes do mundo desde o início desta década foram, com frequência, associados à juventude. No entanto, o termo juventude é reconhecidamente pouco preciso quanto à idade que refere: estariam aqueles que frequentam os anos finais do ensino fundamental incluídos nesse reconhecimento de agência política? No contexto da greve docente da rede pública municipal de ensino do Rio de Janeiro, em 2013, realizamos entrevistas com professoras que participaram desse movimento, considerando que suas narrativas poderiam trazer notícias desse reconhecimento (ou não reconhecimento). Em diálogo com teorizações de Jacques Derrida, Judith Butler e Leonor Arfuch, discutimos sobre os textos produzidos nesses encontros, a partir das noções de performatividade, iteração, interpelação e entrevista narrativa. Assinalamos, nessa leitura, além da já suposta potência da interpelação docente, a força da própria cidade no favorecimento ou obstaculização da agência política desses jovens mais jovens.
\end{abstract}

Palavras-chave: Juventude. Adolescência. Ativismo político. Educação escolar. Diferença.

\section{ABSTRACT \\ POLITICAL ACTIVISM AND YOUTH: TURNSTILES OF THE SCHOOL AND THE CITY FOR THE YOUNGER YOUTH}

The urban occupation movements in various parts of the world since the beginning of this decade were often associated with youth. However, the term youth is admittedly imprecise as age is concerned: were those attending the final years of elementary school included in this recognition of politics agency? In the context of the teaching strike of municipal public schools of Rio de Janeiro in 2013, we conducted interviews with teachers who participated in the movement, considering that their narratives could bring news of that recognition (or non-recognition). In a dialogue with theories of Jacques Derrida, Judith Butler and Leonor Arfuch, such as those of performativity, iteration, interpellation and narrative interview notions, we discuss about the texts produced on such meetings. We note in this reading besides the already supposed power of teacher's interpellation, the strength of the city itself in favor or hindering the politics agency of the younger youth.

Keywords: Youth. Adolescence. Political activism. School education. Difference.

* Doutora em Educação pela Pontifícia Universidade Católica do Rio de Janeiro (PUC-RJ). Professora adjunta da Faculdade de Educação e do Programa de Pós-Graduação em Educação da Universidade do Estado do Rio de Janeiro (UERJ). Líder do Grupo de Estudos sobre Diferença e Desigualdade na Educação Escolar da Juventude (DDEEJ/UERJ). E-mail: miriamsleite@yahoo.com.br 


\section{RESUMEN}

\section{ACTIVISMO POLITICO Y JUVENTUD: TORNIQUETES EN LA ESCUELA Y EN LA CIUDAD PARA LOS JÓVENES MÁS JÓVENES}

Los movimientos de ocupación urbana que tuvieron lugar en diversas partes del mundo en esta década fueron frecuentemente relacionados con la juventud. Sin embargo, el término juventud es reconocido como poco preciso respecto a la edad: ¿estarían incluidos en ese reconocimiento de agencia política, aquellos que frecuentan los últimos años de educación básica secundaria? En el contexto de la huelga docente de la red pública de educación de Río de Janeiro, en 2013, entrevistamos profesoras que participaron en este movimiento, considerando que sus narrativas podrían traer noticias de ese reconocimiento (o no reconocimiento). En diálogo con teorizaciones de Jacques Derrida, Judith Butler y Leonor Arfuch, discutimos las narrativas producidas en esos encuentros a partir de las nociones de performatividad, iteración, interpelación e entrevista narrativa. Observamos, además de la ya supuesta potencia de interpelación docente, la fuerza de la propia ciudad favoreciendo u obstaculizando la agencia política de estos jóvenes más jóvenes.

Palabras clave: Juventud. Adolescencia. Activismo político. Educación escolar. Diferencia.

\section{Introdução}

Cês tão invadindo nosso espaço.

Aí entra alguém, quebra tudo, aí vocês vão querer por a culpa nos estudantes. [...]

Vocês estão fardados, vocês acham que tão no direito. [...]

Cês tão com mandato?

Cês têm algum mandato pra invadir?

Não têm!

Então, dá licença! (YOUTUBE, 2015).

A recorrente enunciação do desinteresse juvenil pela política na contemporaneidade - recorrente não só no senso comum e na grande mídia, como também na pesquisa acadêmica (BOGHOSSIAN; MINAYO, 2009; MAYORGA, 2013) - tem sido desafiada por massivas manifestações públicas de parcelas da população identificadas como jovens, sobretudo a partir das chamadas Jornadas de Junho, que tomaram as ruas do país em 2013. Em 2015, diante da proposta da chamada "reorganização escolar" (GOVERNO..., 2015), por parte do governo do estado de São Paulo, nova movimentação política chama atenção das nossas pesquisas, pela participação daqueles a quem costumamos chamar de jovens mais jovens e constituem nosso foco prioritário de estudo. ${ }^{1}$

Embora pouco noticiada na mídia estabelecida, recorrendo a fontes alternativas de veiculação de notícias - como o Facebook e o Youtube - pudemos identificar que a presença de ativistas que aparentavam idade correspondente à frequência oficialmente esperada nos anos finais do ensino fundamental era flagrante, como se exemplifica na cena transcrita em epígrafe deste texto, em que o protagonista não aparenta mais do que 13 anos e se posiciona, com calma e firmeza, diante de vários policiais, na entrada da sua escola (YOUTUBE, 2015).

Trata-se de recorte da população escolar relativamente pouco focalizado nos estudos acadêmicos (SPOSITO, 2009) e geralmente pouco contemplado, em suas especificidades, nas políticas educacionais (DAVIS et al., 2013): de fato, enquanto os

1 Referência ao Grupo de Estudos sobre Diferença e Desigualdade na Educação Escolar da Juventude/DDEEJ,, coordenado pela autora e vinculado à linha de pesquisa Infância, Juventude e Educação, no Programa de Pós-Graduação em Educação da Universidade do Estado do Rio de Janeiro?ProPED-UERJ. A pesquisa referida neste artigo teve financiamento FAPERJ, e faz parte do projeto Performatividade, diferença e desigualdade na educação escolar do jovem adolescente (LEITE, 2010). 
anos iniciais do ensino fundamental contam com acúmulo considerável de estudos e pesquisas, sobretudo por se tratar do nível de ensino há mais tempo estabelecido no país, e o ensino médio mobiliza o pensamento político e acadêmico pela iminente entrada no mercado de trabalho e vida adulta em geral, os anos finais do ensino fundamental tendem a relativa secundarização. Entretanto, são recorrentes os relatos docentes de dificuldade no trabalho pedagógico nesse nível de ensino (LEITE, 2010). Suspeitamos, contudo, da explicação que naturaliza esse quadro, propondo investigar outros fatores que poderiam concorrer para a sua configuração, e julgamos que a perspectiva teórica e política da diferença pode ser produtiva nesses estudos. Em projeto anterior, a conclusão de estudo etnográfico conduzido ao longo de um ano letivo, em escola da rede pública municipal carioca, apontou que aquilo que entendemos que poderia ser lido como diferença adolescente ${ }^{2}$ era, com frequência, significado pela escola como desigualdade: na medida em que eram subalternizados como "rebeldes sem causa" ou "aborrescentes", justificava-se sua exclusão das instâncias decisórias daquele espaço-tempo e deslegitimavam-se suas reivindicações e questionamentos (LEITE, 2010).

As mobilizações dos estudantes da rede pública de São Paulo evidenciaram a atualidade e urgência da focalização acadêmica desse agrupamento etário. Já desde as Jornadas, indagávamo-nos quanto a deslocamentos que pudessem estar ganhando força

2 A noção de diferença referida neste artigo tem sido construída a partir dos estudos sobre a différance, teorização proposta pelo filósofo Jacques Derrida, que é apresentada em breve síntese na seção que se segue. Quanto à nomenclatura jovem/adolescente/ jovem adolescente/jovem mais jovem, optamos por alternar denominações diversas, como forma de explicitar o reconhecimento das várias identificações atribuídas ao grupo social que discutimos, tanto na produção acadêmica quanto na legislação e em políticas públicas e ainda no senso comum. Diante dessa acentuada instabilidade terminológica, não optamos aprioristicamente por nenhuma dessas expressões, tomando a identificação do grupo social que focalizamos em nossos projetos como importante questão de pesquisa. São enquadrados em nossas pesquisas pelo seu engajamento como estudantes nos anos finais do ensino fundamental e no ensino médio regulares. Com a enunciação das diversas denominações possíveis para esse agrupamento etário, também buscamos expor a multirreferencialidade dos nossos estudos, que dialogam com a sociologia, que usualmente privilegia o termo jovem, com a psicologia, onde é mais frequente a referência ao adolescente (ABRAMO, 2005), e com a filosofia, campo menos referido em tais estudos (SPOSITO, 2009), que, desse modo, não apresenta nenhuma opção mais típica nesse sentido. no contexto acima descrito relativamente à identificação do estudante mais jovem, quando a greve docente da rede municipal do Rio de Janeiro, no final de 2013, tornou tais questões inadiáveis, por diversas razões: víamos, nas passeatas, jovens estudantes uniformizados, lado a lado com professoras grevistas ${ }^{3}$ recebíamos notícias, de testemunhas oculares, a respeito de inesperada aproximação entre ativistas black blocs e professoras; finda a greve, ouvíamos relatos de professoras que narravam um retorno às aulas com visível maior politização por parte dos alunos. Como esses eventos seriam significados pela escola? Como afetariam a identificação dos jovens estudantes, por parte das suas professoras? O reconhecimento de algum nível de autonomia política discente poderia favorecer a significação da juventude adolescente como diferença? Como se interpretaria a brutal repressão policial às manifestações?

Entre as possibilidades de busca de respostas a tais inquietações, realizamos entrevistas com professoras então atuantes em escolas públicas na cidade do Rio de Janeiro, não apenas pelo entendimento da importância da sua perspectiva, como também pela viabilidade dessa interlocução, o que não se repetia em relação aos demais envolvidos: o acesso aos estudantes, bem como ao próprio espaço-tempo da escola, tem sido bastante dificultado pela atual gestão municipal (LEITE, 2011), mas mostrou-se possível quando dirigido às professoras por meio de contatos individualizados. Por certo, geramos nessas interações relatos parciais, mas a mirada teórica de que buscamos nos aproximar já nos interditaria a pretensão do acesso a qualquer tipo de totalidade das instâncias sociais em estudo. Entendemos que, ao problematizarmos narrativas de professoras acerca da participação juvenil no contexto da greve docente carioca de 2013, produzidas em encontros por nós organizados, não buscamos acesso à verdade dos fatos, mas, sim, a como participantes de relevo nesse contexto relatariam tais vivências para nossa investigação. Apostamos que a temática da greve e das Jornadas

3 Embora tenhamos entrevistado pessoas que se identificaram como professores e como professoras, generalizaremos pelo feminino, posto considerarmos que a tradicional invisibilização feminina na linguagem é particularmente incômoda quando se trata da docência, que, como se sabe, é, na sua maior parte, exercida por pessoas que se identificam como mulheres. 
de Junho favoreceriam a enunciação do lugar político projetado pelas professoras entrevistadas para os estudantes foco da nossa pesquisa, o que julgamos ter efetivamente acontecido. Ademais, a recente retomada da mobilização estudantil, em São Paulo, com o visível envolvimento de jovens mais jovens, expôs a pertinência de tais questionamentos.

Apresentamos, neste artigo, a síntese das leituras dos registros dos encontros que promovemos com professoras da rede pública de ensino do Rio de Janeiro, para discutir sobre a participação política da juventude, com especial atenção àqueles identificados como adolescentes. Expomos, inicialmente, os procedimentos de organização e realização das entrevistas - o que inclui esclarecimentos quanto aos sentidos que propomos para as noções teóricas mobilizadas - para, em seguida, abordarmos os dois contextos em que se produziram enunciações de interesse para as indagações dos nossos estudos acerca da possibilidade de ativismo ${ }^{4}$ político entre estudantes mais jovens.

\section{Conversas}

O entendimento de que a contemporaneidade impõe questões político-epistêmicas à pesquisa acadêmica, configuradas, sobretudo, a partir da virada linguística e de sua crítica por perspectivas pós-estruturalistas, somou-se à nossa sensibilidade política para as questões em torno do direito à diferença e levou-nos à leitura de autores que julgamos responder a tal contexto - nomeadamente, Derrida (1991a, 1991b, 2001), Butler (1997, 2008) e Scott (1992). As entrevistas que se discutem a seguir foram concebidas, desenvolvidas e lidas no diálogo com esses textos.

Os questionamentos colocados pelo reconhecimento da não transparência e da precariedade da linguagem e radicalizados pelos argumentos pós-estruturalistas - que duvidam da estabilidade

4 Em acordo com Veiga-Neto, optamos pela expressão "ativismo político", na intenção do afastamento da perspectiva da "militância", conforme definidas pelo autor: "a militância - como uma actio militaris - e o ativismo são, ambos, da ordem do agir para frente, da ação para uma mudança de posição, da ação para uma outra situação diferente da que se tem. Mas enquanto aquela se rege pela lógica da obediência hierárquica, esta se funda na maior liberdade possível e permitida pela combinação entre a díade pensável-dizível e o visível (Foucault, 1999)" (VEIGA-NETO, 2012, p. 272, grifo do autor) das estruturas que abrigariam os jogos diferenciais de construção dos sentidos - afetam os modos de fazer e as focalizações da pesquisa em Educação, ao mesmo tempo em que sinalizam importantes mudanças sociopolíticas na contemporaneidade. Constroem-se simultaneamente ao fortalecimento dos movimentos sociais pelo reconhecimento do direito à diferença, constituindo-se como perspectiva teórica coerente com tal mirada política, que propomos mobilizar para pesquisar sobre a educação escolar da juventude.

A diferença se constitui em questão no dia a dia da sala de aula frequentada pela juventude da atualidade, na medida em que a escola recebe o aluno com deficiência, as falas e os gestos das massas populares, o menino que prefere usar saia, a candomblecista que se orgulha da sua filiação religiosa e não a esconde - enfim, estes são apenas alguns exemplos, pois são muitas as formas como a diferença ganha corpo na escola e, ainda que seja para argumentar pela sua não centralidade face a outras questões do tempo presente, torna-se cada vez mais difícil ignorá-la na pesquisa sobre a educação escolar. Destacamos aqui o que temos denominado como diferença adolescente (LEITE, 2010), por entendermos que a identificação etária costuma marcar as relações escolares com força notável nos anos finais do ensino fundamental e no ensino médio, em dicotomização hierarquizante, que atualiza no espaço-tempo escolar o adultocentrismo em geral prevalente na nossa sociedade.

Com Derrida (1991b, 2001), entendemos tal diferença como différance, neologismo intraduzível que o autor propõe para denominar o movimento contínuo de adiamento de alguma estabilização definitiva dos sentidos e das identificações em geral. Destaque-se que a opção, neste texto, pela palavra identificação no lugar de identidade não é casual, pelo contrário. Assumimos, a partir dos estudos sobre a différance, a recusa à noção de identidade, posto que, historicamente, tendeu a assumir conteúdo essencial e positivo. Desse modo, não atrelamos a identificação juvenil a faixas de idade ou a quaisquer características intrínsecas, sejam da ordem da biologia ou da cultura. Antes entendemos que a identificação jovem/adolescente se constrói contingencialmente em processos performativos - outra noção que demanda esclarecimento, posto 
que não apenas informa sobre o sentido pretendido para a expressão identificação, como também fundamenta a opção pela problematização de narrativas docentes para a discussão dos processos de identificação que aqui focalizamos.

Se a noção de différance foi proposta por Derrida (1991b) na sua leitura desconstrutora das teorizações de Saussure, a concepção de uma identificação performativa do jovem/adolescente tem se configurado, pela recontextualização das proposições da teórica feminista Judith Butler (1997, 2008) acerca do gênero performativo, no âmbito das nossas pesquisas. Conforme já argumentamos em outra publicação: "assim como nas questões de gênero, existem as práticas reguladoras da coerência da idade que, performativamente, dicotomizam e hierarquizam a criança/adolescente/jovem relativamente ao adulto" (LEITE, 2014, p. 148).

Butler (2008) desenvolve a noção de gênero performativo com base na abordagem desconstrutora que Derrida (1991a) propõe para o livro How to do things with words, de autoria do linguista John Austin (1975). Temos apresentado nossa leitura dessa teorização em outras publicações (LEITE, 2014, 2015), e aqui destacaremos apenas os pontos que informaram de forma mais basilar o estudo que motiva este artigo: o questionamento da distinção entre o enunciado performativo e o enunciado constativo (considerando-se que, ao enunciar, também estamos criando a realidade em descrição, posto que a ela atribuímos sentido, e agimos, sentimos e seguimos gerando e afirmando outras significações); e o entendimento de que esse processo de atribuição de sentido/criação de efeitos de realidade se dá pelo que Derrida (1991a) nomeia como iteração. Refere desse modo a repetição social dos sentidos, mas sublinha a impossibilidade de realização plena dessa repetição. Ao enunciar qualquer conteúdo, repetimos palavras e sintaxes que carregam o que o autor chama de restâncias de sentido, que permitem algum nível de reconhecimento e proximidade de referência, porém não trazem qualquer significação estabilizada que independa do contexto da sua enunciação, dado que não se remete a conteúdos positivos alheios à nossa interpretação. Ao repetirmos uma frase, seus elementos ganham sentido na relação com outros tantos que a precederam e a circundam, em composição única que implica deslocamentos quanto ao que aparenta se repetir, posto que todos esses elementos também apresentam significação precária.

As identificações e as significações com que nos organizamos e vivemos nossa vida cotidiana são, portanto, construídas pela permanente e difusa iteração/repetição/deslocamento de sentidos. Pode-se reconhecer algum nível de estabilização - o que Derrida (1991a, p. 198) chama de "grande estabilidade" - oportunizado pela sedimentação de restâncias que, no entanto, não garante fixação imune aos contextos da sua iteração:

Segundo os contextos (segundo tal cultura nacional, na universidade ou fora da universidade, na escola ou alhures, em tal nível de competência ou em outro, na televisão, na imprensa ou num colóquio especializado), as condições da pertinência mínima e do acesso inicial mudarão. (DERRIDA, 1991a, p. 199).

Por concordarmos com tais proposições, julgamos pertinente a discussão de iterações relativas à identificação do estudante jovem adolescente, na medida em que participam dos processos de sedimentação de sentidos que estabilizam, ainda que de modo precário, contingente e disputado, sua identificação - e, ao fazê-lo, contribuem para, performativamente, criar o jovem adolescente de que se fala. Por certo, na escola não se criam sentidos plenamente autônomos em relação às organizações sociais em que se insere; entretanto, nesse contexto, tampouco apenas se reproduz o que é enunciado em outras instâncias: também ali se repetem e se deslocam sentidos do ser/estar estudante jovem adolescente. Entre as muitas iterações que tomam parte nesses processos, priorizamos, na pesquisa, as interpelações docentes.

O sentido aqui atribuído à interpelação parte da argumentação desenvolvida por Judith Butler (1997), em que defende a necessidade de revisão das proposições do filósofo Louis Althusser relativamente a tal expressão. Aproxima-se deste autor quando considera o peso da nomeação pelo outro na construção das identificações e autoidentificações, mas pondera que esse poder é derivativo, não tem sujeito ou ponto originário da sua força. Dependemos dessa interpelação para nossa subjetivação, inserção e reconhecimento 
social, o que, no entanto, não constitui processo linear, determinístico ou controlável em qualquer nível de plenitude. Assumindo as considerações de Butler (1997), ao abordarmos falas de professoras relativamente às identificações do estudante jovem contemporâneo, não supomos poder incontestável ou soberano dessas enunciações em tais processos, mas trabalhamos com a suposição da relevância das iterações que se realizam.

Conforme mencionamos, dado que a aproximação ao seu local de trabalho se anunciava problemática, chegamos às professoras por meio de convergência rizomática (STEHLIK, 2004), alternativa de acesso a grupos sociais cujo contato sistemático esteja por algum motivo inviabilizado. Inicialmente, identificamos nossa busca com a tradicional estratégia de pesquisa "técnica da bola de neve" (RUBIN; BABBIE, 2009), que também se vale dos contatos possíveis, buscando-se multiplicá-los aleatoriamente, mas se distingue da convergência rizomática por pressupor a possibilidade da representação de contextos. Como operamos com a noção de contexto aberto e instável proposta por Derrida (1991a), não os supomos representáveis e tivemos de buscar alternativa teórico-metodológica para orientar essa etapa da pesquisa. O rizoma metáfora que se empresta da teorização de Deleuze e Guatari (1987 apud STEHLIK, 2004) - simboliza a forma de abordagem alternativa que elegemos, sinalizando a abertura e imprevisibilidade que atribuímos aos contextos a que se remete a pesquisa.

Chegamos, desse modo, a um grupo intencionalmente não representativo da totalidade dos professores da rede pública de ensino do Rio de Janeiro: variamos quanto à localização das escolas de atuação, quanto à idade, ao tempo de magistério na rede pública, e área disciplinar. ${ }^{5}$ Destaque-se que,

5 Campo Grande, Cascadura, Centro, Cidade de Deus, Copacabana, Duque de Caxias, Engenho Novo, Grajaú, Inhaúma, Laranjeiras, Leme, Nova Iguaçu, Olaria, Pavuna, Rocinha, São João de Meriti, Vidigal; entrevistamos 4 professores com menos de 30 anos, 6 entre 30 e 40 anos, 3 entre 40 e 50 anos e 4 com mais de 50 anos; de 1 a 40 anos de experiência; 2 professoras de Artes, 2 de Ciências, 3 de Geografia, 5 de História, 2 de Matemática, 1 de Educação Física e 2 de Língua Portuguesa; os locais de realização das entrevistas foram bastante variados, sempre a partir das solicitações das professoras: duas na Universidade sede da pesquisa, uma em um bar no centro da cidade (grupo Centro), duas em bares próximos às escolas, na zona norte, duas na casa das entrevistadas (individual, na zona oeste; grupo História, na zona norte), uma em quiosque em Copacabana. ao diversificarmos as entrevistadas quanto a tais pertencimentos e identificações, não pretendíamos alcançar uma amostra representativa do corpo docente da escola pública do Rio de Janeiro, mas, sim, conter a possível afetação por marcas mais específicas do que a atuação como professora dessa rede. Esclarecemos ainda que, na leitura das narrativas oportunizadas nesses encontros, não percebemos implicações significativas a partir da localização das escolas ou das disciplinas ministradas, daí julgarmos poder omitir a individualização dessas informações. Contudo, na apresentação da nossa leitura das entrevistas, apontamos a faixa etária das professoras citadas, posto que a questão da idade perpassa todo o desenho da pesquisa em discussão.

Depois de dois encontros com caráter experimental, sendo um individual e outro em grupo, fizemos ajustes no planejamento das entrevistas, que passaram a se desenvolver em torno dos seguintes pontos: inserção profissional; atuação e avaliação da greve; participação, na greve, dos jovens, em geral, e dos alunos da escola do entrevistado, em particular. $^{6}$

Entretanto, questionamos, com a teórica feminista Joan Scott (1992), a atribuição apriorística de legitimidade e fidedignidade à narrativa da experiência. A autora pondera que essa perspectiva supõe a transparência, a estabilidade e o controle racional da linguagem e da consciência, bem como a objetividade da experiência, que seria muitas vezes interpretada como "evidência incontestável" (SCOTT, 1992, p. 24, tradução nossa), constituindo momento de acesso direto à realidade. Concordamos com os argumentos da autora, que nos levam a esclarecer que entendemos que as situações de entrevista que criamos oportunizaram a iteração de identificações do estudante jovem adolescente, que não repetiriam em suposta integridade enunciados que circulam na escola e/ou na sociedade em geral,

6 A realização individual ou coletiva seguiu a determinação das próprias entrevistadas, posto que avaliamos que ambos os formatos haviam se mostrado produtivos para a nossa pesquisa: fizemos então 2 entrevistas coletivas (um grupo com 6 professoras e outro com 5 professoras, sendo o primeiro de uma única escola - grupo Centro -, e o segundo, com professoras de várias escolas, amigas entre si, todas graduadas e lecionando na área de História - grupo História), e 6 individuais. Seis das entrevistadas se apresentaram como homens, e 12 como mulheres, sendo que 2 foram também interpeladas como militantes sindicais (atuantes desde o ingresso na rede pública de ensino, na década de 1980). 
mas, sim, atualizariam restâncias de sentidos que já adquiriram relativa estabilidade social e que tendem a implicar efeitos de verdade nesses processos de identificação. Além disso, cumpre explicitar que a interpelação das entrevistadas como professoras ou como professoras sindicalistas não pretendeu defini-las identitariamente, antes teve o propósito de destacar contornos da sua participação nos processos de construção de sentido acerca da juventude adolescente que têm lugar na escola - contornos esses que poderiam (ou não) mostrar-se relevantes no quadro em discussão.

Leonor Arfuch, teórica argentina que tem discutido sobre os gêneros biográficos incorporando o diálogo com proposições do pós-estruturalismo e de autores como Bakhtin e Ricoeur, concorda que, diante do reconhecimento da impossibilidade da literalidade, não faria sentido interpretar a narrativa da experiência "como fonte imediata da verdade" (ARFUCH, 2010, p. 254). Contudo a autora lembra também que o entusiasmo das Ciências Sociais pelo uso da entrevista, a partir da década de 1970, tinha forte motivação política: falava-se na "democratização da palavra", em "dar a voz" àqueles silenciados pela história oficial, afirmando, nesse mesmo gesto, tal voz como "testemunho de verdade" (ARFUCH, 2010, p. 250).

Embora não compartilhemos da perspectiva militante que atribui ao texto acadêmico autoridade para "dar voz" a quem quer que seja, e discordemos, por princípios epistêmicos basilares, de qualquer concepção de verdade exterior aos jogos de linguagem e poder com que conferimos sentido à nossa existência e vida social, preferimos propor conteúdo alternativo no lugar de apenas recusar essa dimensão política da nossa escolha pela entrevista com professoras. Lembramos a argumentação de Costa (2002, p. 93-94), que sublinha que vivemos em permanente luta pela prevalência social de significações e identificações:

Se não contarmos nossas histórias a partir do lugar em que nos encontramos, elas serão narradas desde outros lugares, aprisionando-nos em posições, territórios e significados que poderão comprometer amplamente nossas possibilidades de desconstruir os saberes que justificam o controle, a regulação e o governo das pessoas que não habitam espaços culturais hegemônicos.
De fato, chamou atenção a recorrência da afirmação, por entrevistadas, da satisfação pela oportunidade de expor sua experiência na greve docente carioca, já que "a mídia distorce tudo". ${ }^{7}$ Embora não possamos supor que as narrativas das professoras tragam um relato verdadeiro da atuação de alunos durante e depois da greve, na criação desse espaço-tempo de diálogo entre pesquisa acadêmica e docentes da rede pública de ensino do Rio de Janeiro, assumimos o caráter político dessa escolha, que não se coloca pelo entendimento de qualquer valor intrínseco a um suposto lugar estrutural das professoras no contexto em discussão, mas, sim, pelo reconhecimento da importância política do favorecimento da elaboração e publicização de múltiplas narrativas em torno dos temas que abordamos.

Arfuch (2010, p. 250) lembra ainda que "a memória, longe de reproduzir simplesmente a realidade social, é um lugar de mediação simbólica e de elaboração de sentidos" e propõe "enfatizar o acontecimento do dizer" (ARFUCH, 2010, p. 267). Entendemos que as entrevistas constituíram espaço-tempo em que convidamos as professoras à formulação de tais mediações e elaborações simbólicas, o que nos permitiu registrar iterações de relevo para a nossa pesquisa, em que se deslocaram e/ou se repetiram identificações do jovem estudante da contemporaneidade.

Essas iterações foram lidas na unidade de cada entrevista, em que se buscou identificar o contexto mais imediato da sua enunciação - ou seja, o diálogo entre entrevistada e entrevistadora que oportunizou o enunciado em questão -, o que reconhecemos como artifício heurístico, posto que, conforme já explicitado, concebemos os contextos na perspectiva derridiana, que os afirma abertos, por princípio (DERRIDA, 1991a).

As fronteiras que arbitramos para a identificação desses contextos correspondem ao nosso movimento de agrupamento de enunciados, que considera a dupla determinação que deriva das indagações colocadas pela pesquisa e da abertura aos descaminhos da enunciação contingente. Foram delineadas a partir dos seguintes eixos de interpretação: a)

7 Recorte de registro de narrativa de professora (ELISA, 30/40 anos), ao final de encontro individual, quando foi convidada a acrescentar o que julgasse relevante para concluir a entrevista. 
identificação e discussão de movimentos de deslocamento/repetição de enunciados que a pesquisa acadêmica e a vivência na educação escolar, por parte do grupo de estudos, levam-nos a entender como relativamente estabilizados na atualidade social do país; b) identificação e problematização de possíveis efeitos performativos dos enunciados em questão. Entre os contextos identificados, são a seguir apresentados os dois que trouxeram mais elementos de interesse para a discussão aqui proposta, nomeados segundo as temáticas que privilegiamos na sua identificação: 1) juventude, juventude mais jovem, política na cidade; 2 ) juventude mais jovem, política na escola. Os dois contextos de iteração foram trazidos pela pesquisadora, mas também pelas professoras: destaque-se que a condução da entrevista foi de fato partilhada, conforme se observa nos registros das transcrições, em que é possível verificar que as entrevistadas ocuparam o maior tempo da enunciação nessas conversas e que parcela significativa dos assuntos desenvolvidos foi por elas introduzida.

\section{Juventude, juventude mais jovem, política na cidade}

O tema da greve foi o mais desenvolvido nas falas dos entrevistados, talvez porque tenhamos introduzido essa discussão já no convite para participar da pesquisa, ou talvez porque, como foi de diversas maneiras demonstrado durante as entrevistas, a greve havia mobilizado com força aquelas professoras. ${ }^{8}$ Todavia, por certo, esse contexto de

8 De início, pretendíamos conversar com professoras e gestoras grevistas e não grevistas, porém apenas docentes que haviam participado da greve responderam positivamente ao nosso convite. Para apresentar a proposta e contextualizar a entrevista, referíamos nosso grupo de pesquisa e explicitávamos o interesse em conversar sobre a atuação dos alunos antes, durante e depois da greve. Não houve rechaço explícito por parte das não grevistas, mas foram evocadas impossibilidades diversas, sobretudo dificuldades de agenda devido à necessidade de reposição de aulas. Como as dezenove professoras grevistas entrevistadas também tinham de repor o tempo de greve, acreditamos poder supor que houvesse outras motivações para essas recusas. A greve foi massiva e é possível que as docentes que não participaram do movimento não se sentissem confortáveis com o assunto, dada a sua posição minoritária. Sua indisponibilidade contrastava com a boa receptividade que encontramos entre as grevistas, o que foi explicitado em diversas entrevistas e/ou demonstrado na abertura para a conversa em locais improvisados como bares e praças próximos às suas escolas, ou datas improváveis como a antevéspera do Natal. narrativa foi bastante produtivo para a pesquisa, dado que favoreceu construções de sentido acerca do ser estudante jovem adolescente e de suas possibilidades de atuação política na contemporaneidade que entendemos portadoras de rastros relevantes de vetores concorrentes na fixação dessas identificações, na escola e na sociedade em geral.

A articulação entre a eclosão do movimento grevista e as chamadas Jornadas de Junho de 2013 foi apontada em todas as entrevistas. De início, sem o questionamento direto da pesquisadora, em falas que contavam da greve, as manifestações de junho foram referidas como tendo criado uma situação política que favoreceu o movimento docente e/ ou como exemplo a ser seguido pelo restante da população. Nas entrevistas em que explicitamente perguntamos a esse respeito, as respostas não divergiram das que apareceram sem o direcionamento da questão.

No entanto, a relação do movimento grevista com os ativistas black blocs, então anunciada com alarde pela grande mídia, não foi lembrada nas narrativas das professoras. Foi trazida pela pesquisadora, visando explorar o intrigante enunciado "Black bloc é meu amigo, mexeu com ele, mexeu comigo", que havia sido repetido em coro por milhares de professoras grevistas em assembleia realizada no Clube Municipal, conforme testemunho de membros do nosso grupo de pesquisa e confirmado pelas entrevistadas: teria havido algum deslocamento em relação à atribuição de irresponsabilidade e/ou rebeldia como típicas da juventude? Caso tivesse havido, que efeitos performativos teriam sido gerados?

Embora realizadas em separado, nas entrevistas com professoras atuantes no Sindicato Estadual dos Profissionais de Educação do Rio de Janeiro (SEPE-RJ), a narrativa foi semelhante: "É o que eu falo, eu não tenho nada contra os black blocs, $o$ meu problema é o seguinte: a categoria não aprova esse tipo de postura, de quebra-quebra, não aprova, não aceita, não adianta, é cultural da categoria." (MARLI, Individual, 50/60 anos). Ambas destacaram sua discordância política em relação a esse tipo de ativismo, porém sem menção a termos como "vandalismo" e congêneres.

Em outras entrevistas, essa tensão, em maior ou menor grau, também foi relatada. A negativização 
do ativismo black bloc, pela população em geral, foi mencionada em vários encontros, argumentando-se que, por conta da versão divulgada pela grande mídia, perdia-se apoio popular à greve quando se associava o movimento a esse grupo. Entretanto, é digno de nota que, apesar de terem se registrado enunciados de divergência em relação à estratégia política dos black blocs, não houve adesão aos argumentos mobilizados pela mídia estabelecida na condenação a esses ativistas, pelo contrário.

Murilo: Uma coisa que tô me lembrando aqui, que o Sérgio falou, é que as manifestações são pedagógicas. Eu conheço algumas pessoas que, quando começou a participação dos black blocs nas manifestações, começaram a entoar aquele coro da mídia, que o black bloc é que era quebra-quebra, que era bandido, que era vandalismo, parará-pão-duro. Quando participaram daquela manifestação do 15 de outubro, em que os black blocs defenderam os professores da polícia e essas pessoas estavam no meio, no dia seguinte, o Facebook da pessoa era como se ela nunca tivesse falado mal dos black blocs. Depois do 15 de outubro, o discurso mudou radicalmente, entendeu? Então, o fato de estar ali e de enxergar o fato com os próprios olhos fez com que as pessoas parassem de engolir aquela mensagem e começassem a olhar mesmo o black bloc. (MURILO, Grupo História, 30/40 anos).

Houve também entrevistas em que o deslocamento foi além, não apenas valorizando a atuação política desses ativistas, mas também desestabilizando o usual binarismo adultocentrista jovem $\mathrm{X}$ adulto, em que o primeiro tem sempre e apenas a aprender, e o outro, a ensinar.

Pesquisadora: Artur, eu tô preocupada com a tua hora, porque eu acho que já estourou o tempo que a gente tinha combinado. Tem mais alguma coisa que você quisesse acrescentar a essa nossa conversa?

Artur: Você tem mais alguma outra pergunta?

Pesquisadora: Eu encerrei, tô muito satisfeita.

Artur: Então, é isso. Eu aprendi muito com a rua, solidariedade.

Pesquisadora: Você já tinha tido alguma outra experiência de ativismo desse tipo?

Artur: Não, não. Agora, eu participei de uma reunião com, com a [ativista black bloc], eles estavam resolvendo o Ocupa Ministério Público. Então, eles reuniram o pessoal e eles me chamaram, eu e uma colega, nos chamaram: 'Vamos ali.' Sentou todo mundo, juntou as cadeiras e sentou todo mundo ali. E na hora da apresentação, o pessoal diz, eles não dizem aquilo que eles fazem, mas o movimento em que eles estavam atuando: 'Eu sou do Ocupa', 'Eu sou...' - enfim, cada um foi dizendo o movimento que eles estão atuando. Não existia uma preocupação em dizer: 'Eu sou professor', 'Eu sou artista', embora tivesse ali estudantes de direito, artistas, gente de diversas áreas ali unidas. E eles resolveram em 40 minutos, eles resolveram uma ocupação do Ministério Público com toda a tranquilidade, com uma fluidez - por que, eu não sei. Se é por que existe pouca vaidade e muito foco no problema... Então, a preocupação deles era com os problemas políticos, e, naquela hora, com os moradores de rua. Então, não é ninguém importante pra sociedade, mas eles, reunidos ali, sem empenho financeiro, sem intenção político-partidária, se dispunham a proteger aquele que tava sendo injustiçado pela Justiça. Teve uma hora que eles me perguntaram o quê que eu tinha pra dizer, e eu disse pra eles: 'Gente, eu tô aqui me alfabetizando. Eu tô tendo que me esvaziar pra poder entender o que vocês estão fazendo aqui.' (ARTUR, Individual, 50/60 anos).

Embora recente na rede municipal de ensino, o professor tinha mais de 50 anos de idade e subvertia, com seu enunciado, a hierarquia adultocêntrica já tão consolidada na nossa sociedade: jovens ativistas sabiam o que ele não sabia, ensinavam-lhe sobre atuação política e solidariedade. Essa relação também seria possível com os alunos do ensino fundamental?

Nesse ponto das entrevistas, isto é, quando se falava da presença dos black blocs e/ou de jovens estudantes nas manifestações da greve, dois enunciados foram recorrentes, sem provocação direta da pesquisa: a faixa etária e a cidade como determinantes dessa participação (ou não participação).

A associação entre juventude e disposição para a luta política foi, de algum modo, afirmada na maior parte das entrevistas. Em alguns casos, sem desenvolvimento de justificativa, apenas se repetindo frases como "tem aquela rebeldia do jovem mesmo"; 9 em outros, argumentando-se que

9 "Pesquisadora: Mas você acha que essa greve aconteceu agora por quê?

Sílvia: Ah, acho que teve muita influência das passeatas de junho, né? Tanto jovem na rua, dá até vergonha não fazer 
o jovem teria menos a perder ou que ainda não teria se decepcionado com a política, o que seria comum entre os mais velhos. Contudo, independentemente da explicação para a suposta propensão jovem à atuação política, esta foi em geral referida com simpatia, ainda que, algumas vezes, com certa condescendência - visões que, na maior parte dos casos, não se estenderam aos jovens adolescentes.

Por exemplo, black blocs foram diversas vezes citados como tendo presença importante na defesa dos professores contra a brutalidade da repressão policial em manifestações e ocupações, mas essa identificação (positiva) dependia da idade dos ativistas, não apenas da sua atuação. Quando mais jovens, supunha-se a necessidade da sua proteção e não o contrário.

Marli: Tô eu lá na passeata, aí vem 'uh, uh, uh', aí, quando eu olhei, ai, saí, assim, assustada, 'sou eu, professora', 'ai, garoto, eu acabo com a tua raça!' [risos].

\section{Pesquisadora: [risos].}

Marli: Aí amarrou lá o pano, botou a camiseta, e eu falei: 'Garoto, vai embora, menino! Você não sabe o que é que vai rolar aqui!' [...] (MARLI, Individual, $50 / 60$ anos).

Também se evocou o desinteresse pela política por parte desses jovens mais jovens, o que se explicaria pela sua suposta pouca maturidade.

Pesquisadora: E no Município?

Gil: No Município, não.

Pesquisadora: E o grêmio da sua escola?

Gil: Nada, nem existe.

Pesquisadora: Nem existe?

Gil: Não, não, não. Inexiste... O Município tem muita dificuldade de participação, desse tipo de participação mais politizada, muito difícil. São muito novos. Às vezes quando o aluno chega no nono ano, que ele tá saindo, aí ele tem aquela coisa melhor. Eu tenho um aluno que é ótimo... Que foi meu aluno agora, ele é aluno do nono ano. Ele queria porque queria que a professora chegasse até a ditadura militar, que ele queria estudar. Aí a professora fez até uma aula extra só disso, ela nem dava esse conteúdo. [...] Mas

nada. Se bem que tem aquela rebeldia do jovem mesmo, né? Então, toda hora eles se agitam mesmo." (SILVIA, Individual, 40/50 anos, grifo nosso). é exceção. Agora, ele não participa de movimento. Movimento não tem.

(GIL, Individual, 50/60 anos).

Nesse contexto, pode-se, portanto, assinalar importante pista de enunciação/interpretação e respectivo efeito performativo: os mais jovens não participam, ora porque não têm interesse, ora porque seria perigoso - em ambas as enunciações, falta autonomia, seja no sentido da maturidade política, seja no sentido da possibilidade de autodefesa nos conflitos da rua. Por uma razão ou por outra, naturaliza-se a não participação desse agrupamento etário, o que entendemos contribuir performativamente para o seu pouco engajamento político. Chama atenção, por exemplo, que tenha se verbalizado mais o questionamento da presença do jovem adolescente nas manifestações do que a violência policial que torna tal atividade muito perigosa para todos nós e não apenas para esse grupo social.

Entretanto, a determinação de postura política pela idade não foi repetida sem deslocamentos de relevo. No grupo Centro, apareceu com força o que aqui vamos denominar como interpelações da cidade, que complicam a justificativa da pouca idade para a não participação política dos jovens adolescentes.

Paula: Então, o autoritarismo da escola que a Sílvia coloca, ele é o mesmo numa escola escura e na outra toda pintadinha, bonitinha, mas, é, até o ambiente físico geralmente é muito parecido. Mas na relação com os alunos, eu via lá, é, alunos que viviam no meio da rua, mas no meio da rua na favela do Arará e da Barreira do Vasco, só, é aquela rua. E aqui eles têm uma diferença, que o meio da rua deles é o centro da cidade, então, eles têm que dominar o centro da cidade, né? É uma coisa e tanto, que às vezes muita gente vai fazer isso na faculdade e quando vai.

Pesquisadora: [risos].

Paula: Então, já é uma conquista que eu fico impressionada.

Pesquisadora: É verdade, isso muda muito.

Marília: 'Ah! Sei onde é o CCBB, sei onde é Candelária, a Cinelândia'. Eles circulam por um espaço que é muito rico, né? (PAULA, 50/60 anos; MARÍLIA, 20/30 anos, Grupo Centro). 
Pesquisadora: E os seus alunos, você encontrava com eles nas manifestações?

Márcia: Ah, não! Eles moram todos por aqui, nem iam saber chegar lá. Não, são muito novos, não andam assim pela cidade. (MÁRCIA, Individual, $40 / 50$ anos).

Movimentos de ocupação de espaços públicos que se multiplicaram pelo mundo desde 2011 têm trazido para as manchetes de jornais aspectos das relações entre juventude e cidade que vão além da presença física do ativismo político. Carrano (2003) fala em "cidades educadoras", lembrando a pedagogia cotidiana que tem lugar nesses espaços, para além dos muros da escola. Ressalta a heterogeneidade e imprevisibilidade das vivências educativas que resultam de proposições dos planejadores do urbano em negociação e confronto com as práticas dos atores sociais: "A cidade [...] é um conjunto múltiplo de ação coletiva, elaborada em muitas dimensões, plena de significados, construtora de identidades e identificações" (CARRANO, 2003, p. 24). As entrevistas que realizamos apontam que a cidade parece mesmo participar dos processos de significação da diferença etária adolescente, podendo empoderar ou limitar a autonomia dos atores assim identificados. Conhecer uma área culturalmente valorizada, como é o caso do centro da cidade, pode ser lido como sinal de maturidade - "que às vezes muita gente vai fazer isso na faculdade e quando vai" (PAULA, Grupo Centro, 50/60 anos) - e poder. Entretanto, para conhecer essa região é preciso nela morar, pois a circulação no espaço urbano é sabidamente problemática. $\mathrm{Ou}$ seja, a cidade também participa das interpelações que constituem o que costumamos entender por adolescência.

O sociólogo francês François de Singly (2002) relata pesquisa realizada junto a jovens franceses com idade entre 11 e 13 anos e moradores de centros urbanos, a respeito da sua mobilidade. Uma das conclusões do estudo aponta que, também naquele país, morar na região central das cidades tem favorecido uma maior autonomia a seus jovens mais jovens, na medida em que lhes permite ter acesso a bens culturais diversificados e socialmente valorizados, sem a companhia compulsória de adultos. Nesse mesmo sentido, o ônibus foi enunciado positivamente pelos participantes da pesquisa de Singly, dada a autonomia que pode proporcionar, pelo alargamento do espaço urbano transitável.

De fato, a independência no deslocamento pela cidade não é um ganho menor: também no nosso país, precisar do acompanhamento de responsável mais velho costuma implicar significativos limites de possibilidade de circulação pela cidade, dado que a falta de disponibilidade do adulto constitui mais um obstáculo para o deslocamento do jovem adolescente pela cidade. Contudo, por certo não é o único impedimento para seu livre circular: limites de recursos financeiros também colaboram para restringir a autonomia da sua circulação.

É interessante observar que as Jornadas de Junho de 2013 e as movimentações contra o aumento da tarifa em 2016 assumem, portanto, demanda central para os jovens mais jovens do nosso país quando reivindicam transporte coletivo eficiente e gratuito, ainda que a discriminação etária não seja a preocupação primeira do Movimento Passe Livre: “As catracas do transporte são uma barreira física que discrimina, segundo o critério da concentração de renda, aqueles que podem circular pela cidade daqueles condenados à exclusão urbana" (MOVIMENTO PASSE LIVRE, 2013, p. 15). Ocorre que, desse modo, as catracas segregam em especial os jovens adolescentes que, em grande número, tampouco podem arcar com tais custos, que dobram de valor pela necessidade do acompanhamento adulto.

\section{Juventude mais jovem, política na escola}

Conforme mencionado, foram recorrentes os relatos de pouca ou nenhuma participação dos estudantes dos anos finais do ensino fundamental nas manifestações da greve docente. Registraram-se, nas entrevistas, duas formas de narrar essa ausência: argumentando-se que, pela sua idade, não tinham interesse em política - ou seja, supondo e naturalizando sua ausência da vida política - e/ ou interpretando-a como inviável pelos riscos que traria para esses jovens adolescentes - neste caso, supondo e naturalizando a repressão policial e a consequente necessidade da sua proteção nesse tipo de situação. 
Contudo, tanto o argumento da não participação por desinteresse político quanto o que recorria a questões de segurança foram desestabilizados em diversas narrativas produzidas pelas entrevistas, quando se relataram circunstâncias variadas de mobilização política estudantil.

Marília: Teve duas revoltas na escola, e uma delas eles já chamam de 'revolta do sal', que foi logo... No meio das manifestações de junho, que o pessoal tava reclamando muito da comida da escola, e de fato não tava boa e tal, e aí um dia...

Sonia: Reclamavam porque tinha muito sal. Aí, num ato de punição, a adjunta, um dia, mandou fazer a comida sem sal nenhum.

Marília: E aí, só que isso foi assim... Infelizmente, pra desgraça deles, foi dois dias depois, sei lá, da grande manifestação. Que é que os alunos fizeram? Chegavam no refeitório, tentavam comer, não conseguiam, jogavam tudo fora e foram, e desceram pro pátio. Ah, pra completar, era dia de jogo de amistoso do Brasil às três da tarde. Todas as escolas da região que têm dois turnos iam ser liberadas nesse horário. E eles, como acaba às quatro, não seriam liberados. E aí, quando a gente tá lá embaixo, dali a pouco deu meio dia e quarenta, hora de voltar pra sala, eles cruzaram os braços e falaram: 'A gente não vai voltar não, a gente não almoçou, vai ter aula até as quatro, tem jogo do Brasil às três, vai todo mundo ser liberado.' Aí o diretor desceu com microfone, toda uma comoção. Eu sei que mandaram subir os alunos até duas horas e às duas horas eles foram liberados. E aí, enfim, isso foi uma coisa. E a outra foi agora, né? No retorno da greve, que foi meio... Foi meio, não, foi muito atropelada a decisão sobre reposição, sem consultar toda a comunidade escolar, enfim, uma série de coisas. E aí os alunos tavam tendo aula de sete às cinco, já que é tempo integral, e não de oito às quatro. Só que de sete às cinco corre a mesma quantidade de comida, no mesmo calor, no mesmo barulho e aí eles falaram: 'A gente não dá conta disso.' Eles já tavam construindo a argumentação deles, montando um abaixo assinado e falavam: 'Não pode ser como foi na revolta do sal, a gente tem que ter o que falar quando o diretor descer.' Então eles, assim, avaliando o processo, foi muito legal, sabe? E aí eles organizaram uma manifestação pra um dia, que acabou que foi atropelada e aconteceu antes da hora. Então os organizadores ficaram chateadíssimos, e a gente teve que explicar que era parte do processo. [risos].
Pesquisadora: [risos]..

Solange: Acontecia com a gente também.

Marília: É, então, assim, eles desceram pra entregar o abaixo assinado, mas aí a adjunta viu que tava meio confuso, fechou a porta do refeitório, teve gente que não lanchou, eles começaram a gritar: 'Então a gente vai ser liberado, não vai ter reposição coisa nenhuma!' E aí, nesse dia, eles se organizaram e acabou que a reposição voltou a ser de oito às quatro, não teve mais. Então, assim, conquistas dos alunos...

Pesquisadora: Que interessante.

Marília: É, usarem essa ferramenta, né? De luta.

Solange: Agora, eles falam, né, a palavra arrancar: 'Nós conseguimos arrancar do diretor.' [risos]. (MARÍLIA, 20/30 anos; SONIA, 30/40 anos; SOLANGE, 40/50 anos, Grupo Centro).

Há vários outros exemplos possíveis de relatos de atuação política dos estudantes dos anos finais do ensino fundamental que foram registrados nas entrevistas e que deslocam o enunciado da impossibilidade da participação política devido a alguma suposta imaturidade. Narram uma adolescência que busca atuar de forma organizada no espaço-tempo da cidade em que são autorizados a circular, ainda que sob permanente controle, como costuma acontecer na escola. E a noção de performatividade leva ao questionamento: estudantes adolescentes não atuavam politicamente nas escolas pela sua pouca maturidade intrínseca ou em resposta às interpelações que percebiam?

Em uma das entrevistas, a performatividade do enunciado da imaturidade adolescente foi particularmente evidente:

Pesquisadora: Você notou alguma diferenciação por parte deles, na escola, depois do retorno? Você trabalha em três escolas, né, em alguma delas...

Artur: A gente percebe que eles estão mais aborrecidos, assim como nós estamos mais aborrecidos. Nós estamos voltando a fazer esse tipo de movimento, mas eles estão alienados em relação a isso, né? Mas essa participação popular, a gente percebe que os alunos estão entendendo mais a situação. Por exemplo, os alunos não queriam aula no sábado e eles queriam fazer greve: 'Vamos fazer greve! Vamos parar! Não vamos ter aula!' E começaram a fazer um tumulto na sala, na minha sala. Aí eu parei 
com eles e falei: 'Vamos organizar, que a gente não pode ser desorganizado. Vocês são menores, vocês não podem fazer isso. Se vocês querem fazer isso, precisam da concordância dos pais de vocês.' Então eu orientei que eles conversassem entre eles ali, fiz uma reuniãozinha, separei os representantes. Os representantes desceram, conversaram com a direção. A direção subiu, entendeu a demanda deles e até mudou o plano que eles tinham lá. Nessa escola, eles chamaram os pais pra poder conversar sobre a reposição e o que é que tava acontecendo. (ARTUR, Individual, 50/60 anos).

O professor enuncia a impossibilidade do ativismo político do estudante adolescente não apenas quando a afirma em entrevista (o que fez em diversas passagens do encontro), como também, e sobretudo, quando intervém nessa mobilização e concorre para efetivar seu enunciado: greve só com autorização dos responsáveis, diálogo apenas com representantes acompanhados pelo professor. Como não existe regulação legal ou por regimento escolar que autorize ou não a greve discente, quando o professor condiciona essa atuação à permissão dos responsáveis, contribui de forma bastante concreta para a desmobilização dos alunos: obviamente, não seria possível conseguir tais autorizações em curto prazo, e também nos parece evidente que os estudantes poderiam de fato acreditar que dependeriam do aval adulto para fazer greve, posto que a informação lhes foi dada por uma autoridade docente. Quanto à restrição da negociação aos representantes com professor, entendemos que se trata de mais um exemplo eloquente de criação de realidade que se supõe descrever, isto é, de um enunciado performativo: ao supô-los imaturos, o professor toma diversas atitudes que interditam aos estudantes a oportunidade de não sê-lo, contribuindo, dessa forma, para a criação da realidade que aparentava entender que apenas relatava.

Contudo, a leitura das entrevistas identificou ainda o que consideramos significativa regularidade, que entendemos sinalizar a força da interpelação docente no âmbito escolar: a menção à pouca idade, que justificaria o desinteresse pela política como tipicamente adolescente, coincidiu com certo padrão narrativo referente à atuação das próprias entrevistadas na greve docente.
Quando indagadas sobre o contato com alunos antes, durante e depois da greve, presencialmente (na escola), ou por meio de redes sociais, as docentes que afirmaram que os alunos dos anos finais do ensino fundamental eram muito jovens para o engajamento político também narraram restrições na interação com seus alunos, por questões de ordem legal, e/ou desvalorizaram essa interação em suas falas.

Pesquisadora: É, em relação aos alunos, você disse que teve que criar a sua página, porque, dada a utilização geral, né? Em relação aos alunos, você contatava os alunos por meio do Facebook?

Gil: Não, não.

Pesquisadora: Nem no Estado nem no Município?

Gil: Não, nem quis. Vou te dizer, eu tive um Orkut durante anos e que eu tinha aquele monte de aluno, do Município principalmente, do estado, eles tinham menos contato, mas do Município tinha um monte...

Pesquisadora: No Orkut?

Gil: No Orkut. Mas aí era aquele contato muito... Não tinha nada. Salvo assim, um ou outro ex-aluno meu que já tava no nono ano e me perguntava coisa do tipo: 'Vai ter aula amanhã?', 'A greve acabou?' Isso, no Orkut, quando eu ainda abria o Orkut. Hoje em dia nem tenho aberto mais. Quem me perguntava isso era um aluno meu, que foi meu aluno no sétimo ano e agora tá no nono, que entrava pra falar comigo.

Pesquisadora: Aham.

Gil: Mas no geral ficavam só montando, postando aquelas bobeirinhas. (GIL, Individual, 50/60 anos).

Entretanto, professoras que não afirmavam a pouca idade dos estudantes como impedimento para a atuação política convergiram na narrativa de um tipo de interação que não ignorava alguma diferença adolescente que - ainda que por construção social e não por qualquer condição da natureza - impunha cuidados nessa relação, porém não a inviabilizava. Contaram criar perfis específicos para contato com seus alunos, em separado daqueles destinados a interações de ordem pessoal.

Observe-se que não se registrou, entre as professoras que afirmaram julgar possível uma maior interação com estudantes de menor idade, enunciados que desvalorizavam esse contato, em crítica a 
uma suposta frivolidade dos interesses desses jovens. Em contraste, nas narrativas da inviabilidade dessa relação, enunciaram-se, de forma recorrente, evidências do que se identificava como imaturidade adolescente, flagrantemente negativizadas, como na última citação do professor Gil.

Entendemos que, de um lado, a ocorrência da afirmação da possibilidade de discussão política entre professor e estudante jovem adolescente, e, de outro, a narrativa da frivolidade do seu interesse e/ou da impossibilidade do envolvimento político, sugere o que pode ser interpretado como o poder performativo da interpelação docente: estariam essas professoras falando de adolescentes por acaso bastante distintos entre si ou suas enunciações produziam os estudantes que aparentavam descrever?

Outra recorrência narrativa que aponta também nessa direção diz respeito à própria atuação das docentes na greve: aquelas que relatavam envolvimento dos estudantes adolescentes, na greve ou na escola, quando do retorno às aulas, também narraram seu próprio engajamento na greve em termos distintos daquelas que afirmavam como excepcional a participação política dos seus alunos mais jovens. As primeiras contavam de uma participação em associação com outras professoras da sua escola, enfatizando a realização de discussões com seus alunos antes e depois da greve. Ou seja, esses jovens estudantes, a quem se atribuiu alguma possibilidade de atuação política, estiveram expostos ao ativismo docente coletivo e organizado: vale lembrar mais uma vez, com Derrida (1991a), que o texto performativo, isto é, o enunciado que participa da constituição daquilo que refere, não se restringe à fala e à escrita, incluindo imagens, gestos, ações, instituições. Em outras palavras, a ação política da professora foi também uma iteração de sentidos do que seria a vida em coletivo. Na narrativa do ativismo organizado, deslocava-se o enunciado, socialmente predominante, do individualismo e afirmava-se outra possibilidade de pertença social, que interpretamos ter tido alguma repetição por parte dos alunos, quando estes se engajaram na "revolta do sal" ou se mobilizaram contra formas de reposição de aulas impostas pelas direções das escolas.

Sabemos, no entanto, que há múltiplos condicionantes para a atuação política docente, que, por certo, não está em avaliação. Por exemplo, há que se considerar o peso de certas práticas da Secretaria Municipal de Educação do Rio de Janeiro, antes, durante e depois da greve, que dificultaram o engajamento político das professoras em coletivo organizado nas escolas. Não sendo este o foco da pesquisa, o que aqui se sublinha é a recorrente correspondência verificada nas entrevistas entre narrativas de ativismo docente coletivo e organizado na própria escola e relatos de engajamento político dos estudantes dos anos finais do ensino fundamental.

\section{Considerações}

Os dois eixos de leitura, propostos a partir da perspectiva político-epistêmica da diferença que temos buscado configurar nas nossas pesquisas, apontam, portanto, para a força da interpelação docente e da própria organização urbana na produção da diferença adolescente - no âmbito da pesquisa, nem sempre convertida em desigualdade pelas narrativas das entrevistadas.

Obviamente, e até por coerência teórica, não se atribui poder de determinação a tal interpelação. Não apenas reconhecemos que se trata de processos complexos, de que participam múltiplos vetores em arranjos contingentes, como também insistimos na possibilidade da agência dos envolvidos. Por exemplo, na seção anterior, citamos a mobilização estudantil narrada pelo professor Artur, que interpelou os alunos como desautorizados para aquele engajamento: segundo seu relato, sua intervenção afetou o movimento, mas percebe-se que não pôde impedi-lo - "Porque a agência do sujeito não é uma propriedade do sujeito, uma vontade inerente ou liberdade, mas, sim, um efeito de poder, ela é constrangida, porém não aprioristicamente determinada" (BUTLER, 1997, p. 139, tradução nossa).

No entanto, não se nega desse modo que existe potência na interpelação docente, e entendemos que a educação escolar que se orienta pelo horizonte da democracia radical (MOUFFE, 1996) pode se beneficiar da desconstrução dos argumentos que fundamentam a localização do estudante jovem adolescente em espaço-tempo pré-político.

O poder performativo dessa interpelação depende da sedimentação de uma série de convenções 
sociais de sentido que viabilizam sua efetivação. Nas entrevistas, observamos que, mesmo entre professoras que não negavam a potencialidade política do estudante jovem adolescente, repetiram-se enunciados que sustentavam as interpelações que naturalizavam sua distância do ativismo político. A título de exemplo, destacamos, entre esses enunciados, uma repetição que se expressou pela sua ausência: não há registro do termo adultez ou similar, embora encontremos muitas ocorrências das palavras adolescência e juventude - entendemos que, desse modo, naturaliza-se determinada normalidade da existência, qual seja, a vida adulta. Assim como não costumamos falar sobre branquidade, tampouco costumamos generalizar em torno da adultez.

Entre as generalizações enunciadas em torno da juventude, chamou atenção a pouca divergência relativamente ao enunciado do ativismo político como característico desse agrupamento etário. Se a afirmação da imaturidade política da faixa etária em estudo foi por diversas vezes desconstruída, a atribuição de ímpeto contestador à juventude encontrou menor dúvida nas falas das entrevistadas. Observe-se que, em ambos os enunciados, compromete-se a agência política em geral: se os adolescentes não têm condições de praticá-la, no caso dos jovens, narra-se tal engajamento como uma fase, o que, por definição, supõe superação pelo tempo. Identificamos, portanto, na afirmação da imaturidade política do adolescente e da natureza revolucionária do jovem, uma mesma enunciação performativa, que contribui para afastar o horizonte do ativismo político da sociedade em geral e não apenas desses agrupamentos etários.

Quanto à interpelação pela cidade, materializada nas interdições à circulação adolescente, propomos como principal conclusão que a reflexão aqui desenvolvida sobre a condição desse grupo nos con- vida à atenção para o espaço-tempo urbano como sede de importantes disputas sociais da atualidade, que incluem, entre inúmeros outros elementos, a participação na construção social da nossa juventude adolescente. Com Negri (2010, p. 208):

Nós pensamos que a metrópole é um recurso, um recurso excepcional e excessivo, mesmo quando a cidade está constituída por favelas, barracos, caos. À metrópole não podem ser impostos nem esquemas de ordem, prefigurados por um controle onipotente (pela terra e pelo céu através de guerra e polícia), nem estruturas de neutralização (repressão, amortecimento etc.) que se querem internas ao tecido social. A metrópole é livre. A liberdade da metrópole nasce da construção e reconstrução que a cada dia ela opera sobre si mesma e de si mesma.

Das ruas partimos, ao espaço-tempo urbano retornamos para finalizar esta reflexão.

Nas cidades, multidões tomaram as ruas de norte a sul no país, em 2013, para lutar pelo passe livre e contra o aumento do preço das passagens, ocupando-as pelo direito de nelas circular e, desse modo, revivê-las em bases democráticas mais radicais. Em 2015, jovens estudantes retomam as ruas de diversas cidades do estado de São Paulo, em defesa das suas escolas. Em 2016, a mobilidade urbana retorna à pauta de movimentos juvenis, que, ao gritarem por mudanças, já tratavam de transformar a urbanidade. Inquietam a cidade e animam outras movimentações, como lembrado pelas entrevistadas.

Todos esses movimentos subvertem o adultocentrismo que tende a prevalecer nas nossas organizações sociais, inclusive na escola. Jovens mais jovens demonstram a maturidade política de que são capazes e nos motivam a trabalhar também pela liberação das catracas etárias construídas pela performatividade dos enunciados adultocentristas, na cidade e na escola.

\section{REFERÊNCIAS}

ABRAMO, Helena. W. O uso das noções de adolescência e juventude no contexto brasileiro. In: FREITAS, Maria Virgínia de (Org.). Juventude e adolescência no Brasil: referências conceituais. São Paulo: Ação Educativa, 2005. p. 19-39.

ARFUCH, Leonor. O espaço biográfico. Dilemas da subjetividade contemporânea. Tradução de Paloma Vidal. Rio de Janeiro: EdUERJ, 2010.

AUSTIN, John Langshaw. How to do things with words. Cambrige: Harvard University Press, 1975. 
BOGHOSSIAN, Cintia Ozon; MINAYO, Maria Cecília. Revisão sistemática sobre juventude e participação nos últimos 10 anos. Saúde \& Sociedade, São Paulo, v. 18, n. 3, p. 41-423, 2009. Disponível em: <http://www.scielo. br/pdf/sausoc/v18n3/06.pdf>. Acesso em: 16 jan. 2016.

BUTLER, Judith. Problemas de gênero. Feminismo e subversão da identidade. Tradução de Renato Aguiar. São Paulo: Civilização Brasileira, 2008.

Excitable speech. A politics of the performative. New York: Routledge, 1997.

CARRANO, Paulo. Juventudes e cidades educadoras. Petrópolis, RJ: Vozes, 2003.

COSTA, Marisa Vorraber. Pesquisa-ação, pesquisa participativa e política cultural da identidade. In: COSTA, Marisa Vorraber (Org.). Caminhos investigativos III. Outros modos de pensar e fazer pesquisa em educação. Rio de Janeiro: DP\&A, 2002. p. 93-118.

DAVIS, Claudia Leme Ferreira. Et al. Os esquecidos anos finais do ensino fundamental: políticas públicas e a percepção de seus atores. In: REUNIÃO ANUAL DA ASSOCIAÇÃO NACIONAL DE PESQUISA E PÓS-GRADUAÇÃO EM EDUCAÇÃO, 36, Goiânia, 2013. Anais eletrônicos... Goiânia: ANPEd, 2013. Disponível em: $<\mathrm{http}: / /$ www.anped.org.br>. Acesso em: 20 jan. 2016.

DERRIDA, Jacques. Posições. Tradução de Tomaz Tadeu da Silva. Belo Horizonte: Autêntica, 2001.

Limited Inc. Tradução de Constança Marcondes Cesar. Campinas, SP: Papirus, 1991a.

Diferença. In:

. Margens da Filosofia. Tradução de Joaquim Torres Costa e Antonio M. Magalhães. Campinas, SP: Papirus, 1991b. p. 33-64.

GOVERNO de São Paulo anuncia o fechamento de 94 escolas. 340 mil alunos precisarão ser transferidos. Huffpost Brasil, 26 out. 2015. Disponível em: <http://www.huffpostbrasil.com/2015/10/26/governo-alckmin-fecha-escolas_n_8389920.html>. Acesso em: 19 jan. 2016.

LEITE, Miriam. Em desconstrução: textos e contextos na educação escolar do jovem mais jovem. In: LEITE, Miriam; GABRIEL, Carmen Teresa (Org.). Linguagem, discurso, pesquisa e educação. Rio de Janeiro: De Petrus, 2015. p. 321-350.

Performatividade: inscrições, contextos, disseminações. Práxis Educativa, Ponta Grossa, PR, v. 9, n. 1, p. 141-165, jan./jun. 2014. Disponível em: <http://www.revistas2.uepg.br/index.php/praxiseducativa >. Acesso em: 08 ago. 2017.

Políticas públicas e escola: sobre estatísticas, professores e diferença. In: FONTOURA, Helena. (Org.). Políticas públicas, movimentos sociais. Desafios à pós-graduação em educação em suas múltiplas dimensões. Rio de Janeiro: Associação Nacional de Pesquisa e Pós-Graduação em Educação, 2011. p. 91-103. (Coleção ANPEd Sudeste). Disponível em: <http://www.fe.ufrj.br/anpedinha2011/ebook3.pdf>. Acesso em: 03 fev. 2016.

Adolescência e juventude no ensino fundamental: signifixações no contexto da prática curricular. Revista Teias, Rio de Janeiro, v. 11, n. 22, p. 55-74, 2010. Disponível em: <http://www.e-publicacoes.uerj.br/index.php/ revistateias/article/view/24115>. Acesso em: 03 fev. 2016.

MAYORGA, Claudia. Pesquisar a juventude e sua relação com a política - notas metodológicas. Estudos de Psicologia, Natal, v. 18, n. 2, p. 343-350, abr.jun. 2013. Disponível em: <http://www.scielo.br/pdf/epsic/v18n2/ v18n2a21.pdf>. Acesso em: 19 jan. 2016.

MOUFFE, Chantal. O regresso do político. Tradução de Ana Cecília Simões. Lisboa, PT: Gradiva, 1996.

MOVIMENTO PASSE LIVRE. Não começou em Salvador, não vai terminar em São Paulo. In: MARICATO, Ermínia (Org.). Cidades rebeldes. São Paulo: Boitempo/Carta Maior, 2013. p. 13-18.

NEGRI, Antonio. Dispositivo metrópole. A multidão e a metrópole. Tradução de Désirée Tibola. Et al. Revista Lugar Comum, n. 25-26, p. 201-208, dez. 2010. Disponível em: <http://uninomade.net/lugarcomum/25-26/>. Acesso em: 19 jan. 2016.

RUBIN, Allen; BABBIE, Earl. Essencial research methods for social work. Connecticut: Cengage Learning Inc., 2009.

SCOTT, Joan. Experience. In: BUTLER, Judith; SCOTT, Joan. Feminists theorize the political. New York: Routledge, 1992. p. 22-40. 
SINGLY, François de. La liberté de circulation de la jeunesse. Récherches et Prévisions, Paris, n. 67, p. 01-29, 2002. Disponível em: $<$ http://ville-en-mouvement.pagesperso-orange.fr/adolescent/adolescents.pdf $>$. Acesso em: 19 jan. 2016.

SPOSITO, Marília. P. (Org.). O Estado da arte sobre juventude na pós-graduação brasileira: Educação, Ciências Sociais e Serviço Social (1999-2006). Belo Horizonte: Argumentum, 2009.

STEHLIK, Daniela. From "Snowball” to "Rhizome": a rethinking of method. Rural Society, v. 14, n. 1, p. 36-45, 2004. Disponível em: <http://www.tandfonline.com/doi/abs/10.5172/rsj.351.14.1.36?journalCode=rrso20\#.VQblPI54rPw>. Acesso em: 20 jan. 2016.

VEIGA-NETO, Alfredo. É preciso ir aos porões. Revista Brasileira de Educação, Rio de Janeiro, v. 17, n. 50, p. 267-492, maio/ago. 2012. Disponível em: <http://www.scielo.br/pdf/rbedu/v17n50/v17n50a02.pdf >. Acesso em: 20 jan. 2016.

YOUTUBE. Garoto “enfrenta” policial militar em escola ocupada em São Paulo. 2015. Disponível em: $<$ https:// www.youtube.com/watch?v=nT2aieQC55A>. Acesso em: 19 jan. 2016.

Recebido em: 01/09/2016

Aprovado em: 20/07/2017 